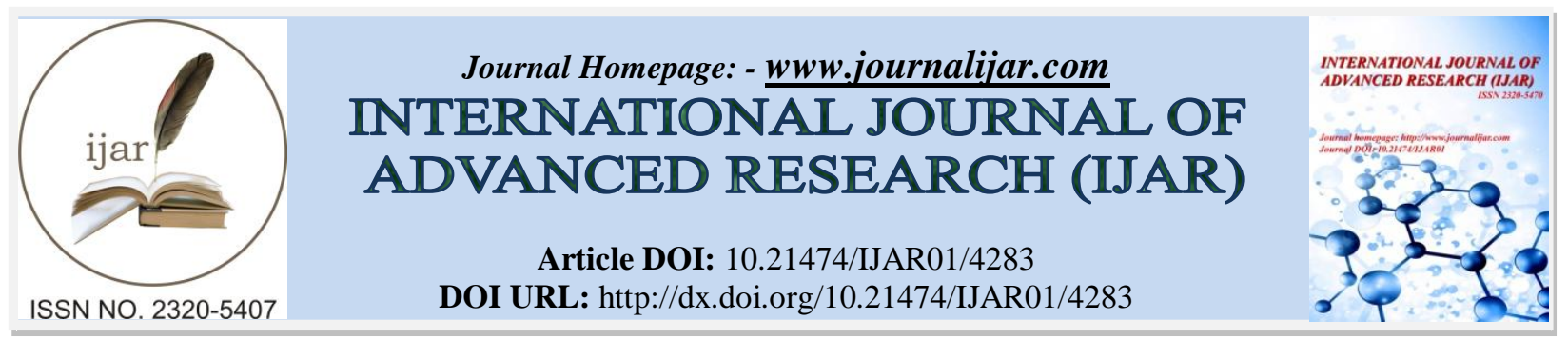

RESEARCH ARTICLE

\title{
ANALYSIS OF STEVIOL GLYCOSIDES FROM Stevia rebaudiana BY USING HIGH PERFORMANCE LIQUID CHROMATOGRAPHY AND REFRACTOMETER, HENCE THE CORRELATION BETWEEN BOTH ANALYSER.
}

A.H. Nur Sabreena ${ }^{1},{ }^{*}$ Y. Nor Azma ${ }^{1}$, A. Asmah ${ }^{1}$ and O. Mohamad ${ }^{2}$.

1. Faculty of Plantation and Agrotechnology, Universiti Teknologi MARA, 40450 Shah Alam, Selangor, Malaysia.

2. Faculty of Agricultural, Universiti Putra Malaysia, 43400 Serdang, Selangor, Malaysia.

\section{Manuscript Info}

Manuscript History

Received: 28 March 2017

Final Accepted: 30 April 2017

Published: May 2017

\section{Abstract}

The sweet diterpene glycosides extracted from the leaves of Stevia rebaudiana (Bert) Bertoni are of increasing interest in recent years as possible sugar substitutes. The approach for this study was towards farmers and household which more applicable for them to use portable refractometer rather than analysis in laboratory using HPLC. Other than that, this finding could be a help in reducing cost due to high costing of HPLC. Our objectives were to investigate the application of refractometer in analysis of steviol glycosides and its correlation with HPLC. The calibration curve for standard stevioside and Reb A shows the value of $R^{2}, 0.9903$ and 0.9901 respectively. The results obtained from the MINITAB software version 16, shows the Pearson coefficient, $r$ was 0.986 and the $\mathrm{P}$-value shows the significant value which was $0.000(p<0.05)$. Besides, the scatter plot shows the linear correlation for both analyser.

Copy Right, IJAR, 2017,. All rights reserved.

\section{Introduction:-}

Stevia was first cultivated commercially in Paraguay in the year 1964. Since that, it has been widely cultivates in several countries such as Brazil, Korea, Mexico, United States, Indonesia, Tanzania and Canada. China has been utilized Stevia since 1985 and currently Stevia production is centered in this country (Puri, Sharma, \& Tiwari, 2011). The example for classes of phytochemical such as alkaloids, flavonoids, saponins, phenolics, tannins, terpenes and glycosides. As for Stevia rebaudiana, it was included in glycosides and terpenes that have been called diterpene glycosides (Doughari, 2012). Steviol glycosides like Stevioside and Rebaudioside A are the compound which has been widely studied among those sweet compounds of plant origin. A number of researchers have reported that Stevia are beneficial for humankind in the aspect of health due to its low calorie properties (KobusMoryson \& Gramza-Michałowska, 2015)

Most of the in vivo researches were using HPLC based on its accuracy in analysis of data for each of steviol glycosides compound. The popularity of HPLC is due to several reasons which were, it offers unsurpassed precision, specificity, sensitivity, and reproducibility. Furthermore, powerful microcomputers and user-friendly software automate the running of samples and collection and processing of data. Other than that, current columns, especially $\mathrm{C}_{18}$ packings, separate a very wide variety of samples, and a variety of on-line detectors provide a means to detect virtually any compound (Lambeth \& Muhonen, 1994). However, there were disadvantages of HPLC include tedious 
sample preparation procedures, large volumes of eluting solutions and additives as well as the total analysis time. (Wang et al., 2009).

In this study, refractometer will be used for the analysis of the content of steviol glycosides as a preliminary analysis. Handheld digital refractometers are convenient, often have automatic temperature compensation (ATC), and readings are less subjective. They work on the principle that light entering a prism has a unique characteristic. That characteristic is represented by a value on a scale in units known as \% Brix (Vasquez \& Mueller, 2001).

\section{Materials and Method:-}

Materials:-

Dried leaves of Stevia bought from China through the Stevia Sugar Coorporation in Malaysia The standard powder of stevioside (LGC STANDARD CDX-00019353-050) and rebaudioside A (LGC STANDARD CDX-00018222050) were from IT Tech company. Distilled water which has been filtered using filteration set. High Performance Liquid Chromatography (HPLC) (Agilent Technology) required stevioside and rebaudioside A powder, acetonitrile (Merck, USA), methanol (Merck, USA) and water (mobile phase). Refractometer was purchased from Surechem Sdn Bhd (Sri Petaling, Malaysia).

\section{Methods:-}

\section{Extraction of Stevia:-}

The Stevia was extracted by following three parameters that has been chosed which were immersion temperature $\left({ }^{\circ} \mathrm{C}\right)$, Particle size $(\mathrm{mm})$, and Immersion duration (min). An amount of $1 \mathrm{~g}$ of dried leaves was extracted with 100 $\mathrm{mL}$ distilled water using steeping method. Water bath and thermometer are used to control the temperature of extract. The crude extract was then filtered using Whatman filter paper no. 1. Distilled water act as a control in this experiment.

\section{Determination using Refractometer (\% Brix):-}

After the extraction process, the crude extract will be analyzed using refractometer to detect the total soluble solid. The range of refractometer that has been used was from $0 \%$ to $56 \%$. The refractometer need to be calibrated after reading first sample to avoid error in reading.

\section{Determination using HPLC (\%):-}

Preparation of stock solution was prepared in methanol (Merck, USA). The standard of stevioside and rebaudioside A were prepared in $0.1,0.2,0.3,0.5,0.8,1.0,2.0,3.0,5.0,8.0$ and $10.0 \mathrm{mg} / \mathrm{mL}$ for both standards used (rebaudioside A and stevioside). All the standard was injected at the three replicate and the value reported as the mean. The areas of the peaks of each standard from total ion chromatogram (TIC) were used to make the respective standard curves. HPLC operating conditions incorporated an isocratic mobile phase, acetonitrile : water (80 : 20), $\mathrm{pH} 5$ adjusted with acetic acid, at a flow rate of $1.0 \mathrm{~mL} \mathrm{~min}^{-1}$, wavelenght at $210 \mathrm{~nm}$, with $5 \mu \mathrm{L}$ injections and a run time of $5 \mathrm{~min}$. The crude extracts which has been extracted using water was analyzed using Liquid Chromatography Time of Flight (LC-TOF) from Agilent Technology Series 1200 and were separated using Inertsil Column C-18 (Agilent Technology) with $250 \mathrm{~mm}$ x $4.6 \mathrm{~mm}$, i.d., $5 \mu \mathrm{m}$. Flow rate was $1.0 \mathrm{~mL} / \mathrm{min}$ and injection volume was $5 \mu \mathrm{L}$ equipped with UV-DAD SL detector (Agilent Technology). After each injection, the needle was washed with deionized water. All samples and standards were filtered through $0.24 \mu \mathrm{m}$ Millipore filters before running the samples to avoid impurities that affect the baseline.

\section{Result and Discussion:-}

Figure 1 shows the high level standard chromatogram of stevioside and Reb A, eluting in that order. This 10.0 $\mathrm{mg} / \mathrm{mL}$ standard contained $10 \mathrm{mg} / \mathrm{mL}$ of Reb A and $10 \mathrm{mg} / \mathrm{mL}$ for stevioside. By using Reb A and stevioside as examples, Figure 4 shows the linearity over $0.1 \mathrm{mg} / \mathrm{mL}$ to $10 \mathrm{mg} / \mathrm{mL}$ concentration range. Both were found to be exceptionally linear within their ranges. It should be noted that the upper concentrations were chosen to accommodate the expected high-end concentrations within the analyzed samples and that the actual upper limit of linearity may be higher. 


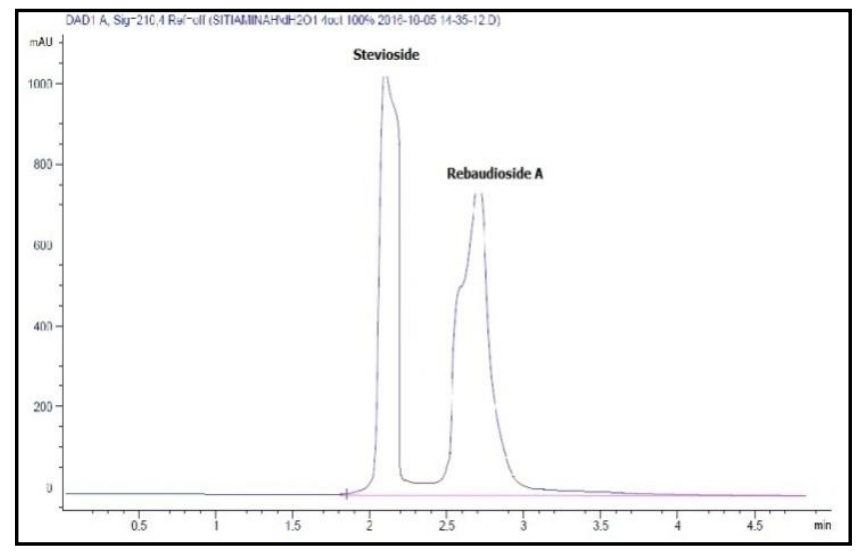

Figure 1:- Chromatogram of standard stevioside and rebaudioside A $10.0 \mathrm{mg} / \mathrm{mL}$, application volume - $5 \mu \mathrm{L}$

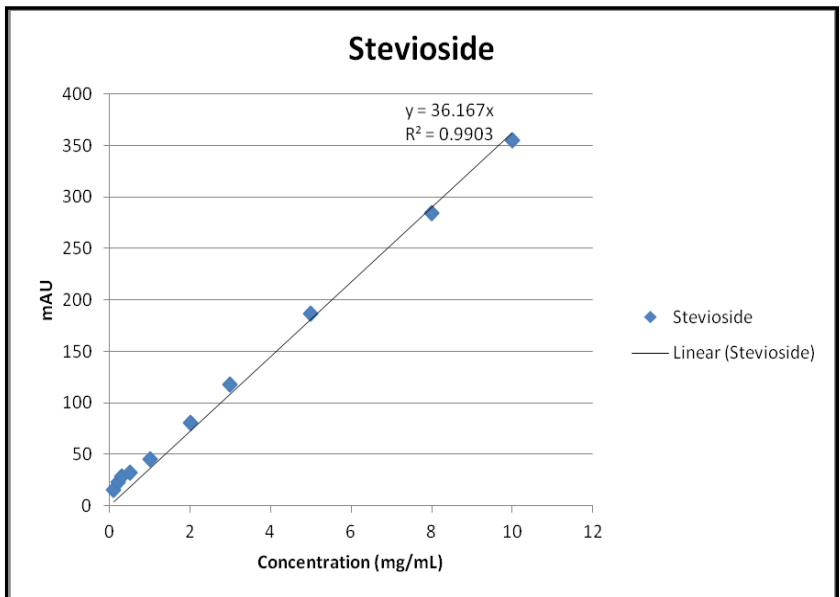

Figure 2:- Standard curve of Stevioside.

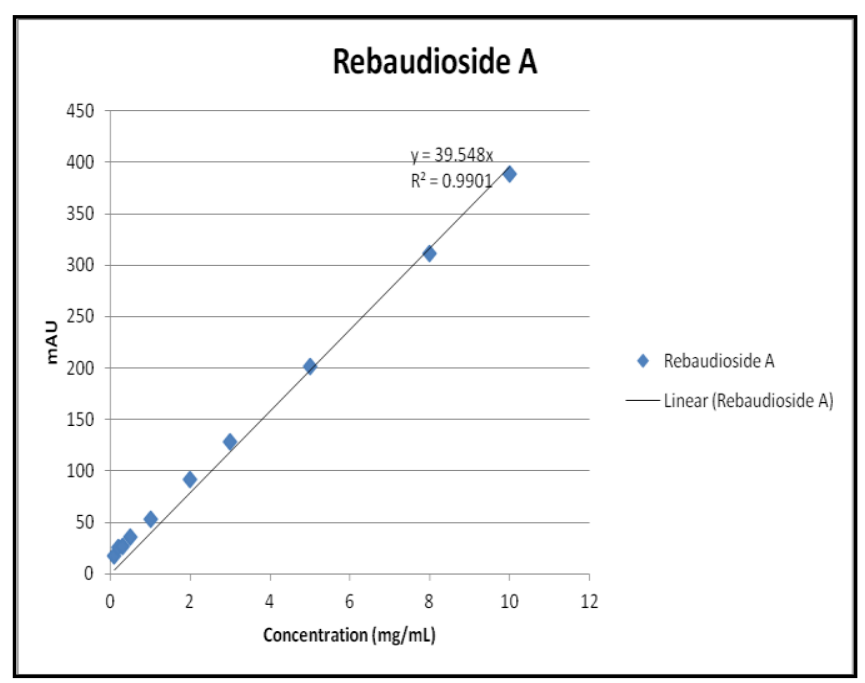

Figure 3:- Standard curve of Rebaudioside A. 
Table 1:- Results of Stevia compound from HPLC (\%) and \% Brix.

\begin{tabular}{|c|c|c|c|}
\hline \multirow[t]{2}{*}{ No } & \multirow[t]{2}{*}{ Samples } & HPLC \% & Brix $(\%)$ \\
\hline & & China & China \\
\hline 1 & $25^{\circ} \mathrm{C} 1.0 \mathrm{~mm} 2 \mathrm{~min}$ & $0.9 \pm 0.1$ & $1.0 \pm 0.17$ \\
\hline 2 & $75^{\circ} \mathrm{C} 1.0 \mathrm{~mm} 2 \mathrm{~min}$ & $1.12 \pm 0.1$ & $1.2 \pm 0.1$ \\
\hline 3 & $25^{\circ} \mathrm{C} 2.0 \mathrm{~mm} 2 \mathrm{~min}$ & $0.48 \pm 0.1$ & $0.5 \pm 0.1$ \\
\hline 4 & $75^{\circ} \mathrm{C} 2.0 \mathrm{~mm} 2 \mathrm{~min}$ & $0.75 \pm 0.05$ & $0.8 \pm 0.17$ \\
\hline 5 & $25^{\circ} \mathrm{C} 1.0 \mathrm{~mm} 4 \mathrm{~min}$ & $1.02 \pm 0.05$ & $1.2 \pm 0.17$ \\
\hline 6 & $75^{\circ} \mathrm{C} 1.0 \mathrm{~mm} 4 \mathrm{~min}$ & $1.85 \pm 0.08$ & $1.3 \pm 0.1$ \\
\hline 7 & $25^{\circ} \mathrm{C} 2.0 \mathrm{~mm} 4 \mathrm{~min}$ & $0.55 \pm 0.07$ & $0.6 \pm 0.1$ \\
\hline 8 & $75^{\circ} \mathrm{C} 2.0 \mathrm{~mm} 4 \mathrm{~min}$ & $0.81 \pm 0.03$ & $0.8 \pm 0.1$ \\
\hline 9 & $8.0^{\circ} \mathrm{C} 1.5 \mathrm{~mm} 3 \mathrm{~min}$ & $0.56 \pm 0.05$ & $1.0 \pm 0.2$ \\
\hline 10 & $92^{\circ} \mathrm{C} 1.5 \mathrm{~mm} 3 \mathrm{~min}$ & $1.72 \pm 0.04$ & $1.8 \pm 0.17$ \\
\hline 11 & $50^{\circ} \mathrm{C} 0.5 \mathrm{~mm} 3 \mathrm{~min}$ & $1.64 \pm 0.05$ & $1.7 \pm 0.26$ \\
\hline 12 & $50^{\circ} \mathrm{C} 2.0 \mathrm{~mm} 3 \mathrm{~min}$ & $0.61 \pm 0.03$ & $0.5 \pm 0.1$ \\
\hline 13 & $50^{\circ} \mathrm{C} 1.5 \mathrm{~mm} 1.3 \mathrm{~min}$ & $0.93 \pm 0.06$ & $1.1 \pm 0.1$ \\
\hline 14 & $50^{\circ} \mathrm{C} 1.5 \mathrm{~mm} 4.7 \mathrm{~min}$ & $1.48 \pm 0.06$ & $1.5 \pm 0.17$ \\
\hline 15 & $50^{\circ} \mathrm{C} 1.5 \mathrm{~mm} 3 \mathrm{~min}$ & $1.34 \pm 0.06$ & $1.5 \pm 0.1$ \\
\hline 16 & $50^{\circ} \mathrm{C} 1.5 \mathrm{~mm} 3 \mathrm{~min}$ & $1.34 \pm 0.06$ & $1.5 \pm 0.1$ \\
\hline 17 & $50^{\circ} \mathrm{C} 1.5 \mathrm{~mm} 3 \mathrm{~min}$ & $1.34 \pm 0.06$ & $1.5 \pm 0.1$ \\
\hline 18 & $50^{\circ} \mathrm{C} 1.5 \mathrm{~mm} 3 \mathrm{~min}$ & $1.34 \pm 0.06$ & $1.5 \pm 0.1$ \\
\hline 19 & $50^{\circ} \mathrm{C} 1.5 \mathrm{~mm} 3 \mathrm{~min}$ & $1.34 \pm 0.06$ & $1.5 \pm 0.1$ \\
\hline 20 & $50^{\circ} \mathrm{C} 1.5 \mathrm{~mm} 3 \mathrm{~min}$ & $1.34 \pm 0.06$ & $1.5 \pm 0.1$ \\
\hline
\end{tabular}

Table 1 shows the results of Stevia extracts that being analysed using HPLC and refractometer. The 20 samples was optimised using RSM from the previous paper (A.H. Nur Sabreena, 2017). Based on the results, the higher the temperature, the more compound being extract out. Besides, the smaller the size of particle, the more compound being extract out. Lastly, the more duration taken for Stevia extraction, the higher values obtained. Those parameters suggested were among the most important factors that affect the extraction of Stevia have been explored in several studies (Abou-Arab, Abou-Arab, \& Abu-Salem, 2010; Afandi, Sarijan, \& Shaha, 2013).

In order to justify the usefulness of the refractometer, the correlation methods have been established, between the results obtained for Stevia samples with both HPLC and biosensor methods. First of all, the expected response of the biosensor readings that present in Stevia was calculated according to its real content estimated by HPLC and its corresponding sensitivity established with biosensor. Table 1 shows the result obtained from two analysis (HPLC and refracrometer). Eventually, these individual responses was analyse using Pearson correlation from MINITAB Software version 16. The result obtained shows that Pearson coefficient, $\mathrm{r}$ values is 0.986 , while the $\mathrm{P}$-value is 0.000 which shows the significant value $(\mathrm{p}<0.05)$. This shows that refractometer might be an alternative to the HPLC utilisation.

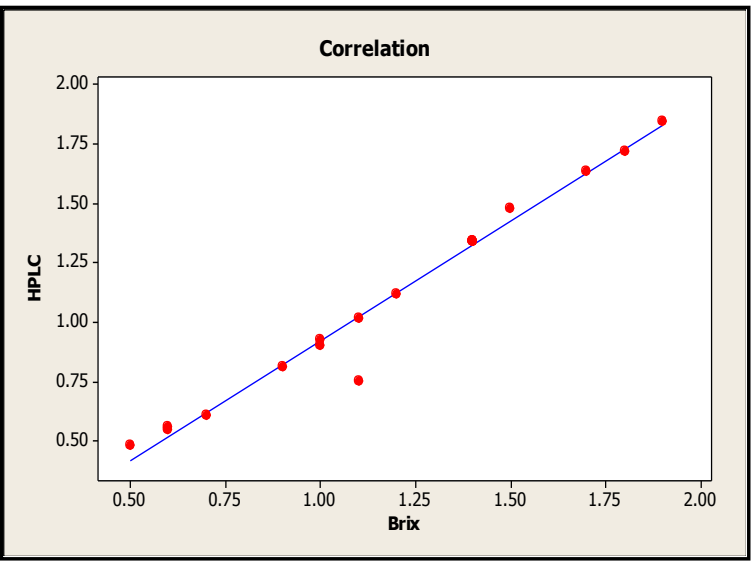

Figure 4:- Scatter Plot of HPLC vs Brix. 
The Pearson coefficient was used to measure correlations of the values between HPLC and refractometer. $P$-values were then assigned based upon the frequency with which Pearson coefficients generated from randomly permuted data exceeded those generated from the observed data (Singh et al., 2002)

\section{Conclusion:-}

Based on the results obtained, there were correlation in values between HPLC and refractometer. Therefore, utilization of refractometer was relevant for preliminary analysis. However, it must be supported by the continuous research for others type of HPLC in order to get more accurate answer. In addition, this research could be a help for farmers to obtain the readings of Stevia they planted as it is more applicable due to the simple method of extraction and analysis.

\section{References:-}

1. A.H. Nur Sabreena, Y. N. A., O. Mohamad (2017). RESPONSE SURFACE METHODOLOGY FOR OPTIMISATION OF PARAMETERS FOR EXTRACTION OF Stevia rebaudiana USING WATER, H2O. IIOABJ, 8, 8.

2. Abou-Arab, A. E., Abou-Arab, A. A., \& Abu-Salem, M. F. (2010). Physico-chemical assessment of natural sweeteners steviosides produced from Stevia rebaudiana Bertoni plant. African Journal of Food Science, 4(5), 269-281.

3. Afandi, A., Sarijan, S., \& Shaha, R. K. (2013). Optimization of rebaudioside a extraction from Stevia Rebaudiana (Bertoni) and quantification by high perfomance liquid chromatography analysis. Journal of Tropical Resources and Sustainable Sciences, 1(1), 62-70.

4. Doughari, J. H. (2012). Phytochemicals: Extraction methods, basic structures and mode of action as potential chemotherapeutic agents: INTECH Open Access Publisher.

5. Kobus-Moryson, M., \& Gramza-Michałowska, A. (2015). DIRECTIONS ON THE USE OF STEVIA LEAVES (STEVIA REBAUIDANA) AS AN ADDITIVE IN FOOD PRODUCTS. Acta Sci. Pol. Technol. Aliment, 14(1), 5-13.

6. Lambeth, D. O., \& Muhonen, W. W. (1994). High-performance liquid chromatography-based assays of enzyme activities. Journal of Chromatography B: Biomedical Sciences and Applications, 656(1), 143-157.

7. Puri, M., Sharma, D., \& Tiwari, A. K. (2011). Downstream processing of stevioside and its potential applications. Biotechnology Advances, 29(6), 781-791.

8. Singh, D., Febbo, P. G., Ross, K., Jackson, D. G., Manola, J., Ladd, C., . . . Richie, J. P. (2002). Gene expression correlates of clinical prostate cancer behavior. Cancer cell, 1(2), 203-209.

9. Vasquez, S., \& Mueller, S. (2001). Refractometer calibration, use and maintenance. USA (CA): University of California Cooperative Extension Fresno County.

10. Wang, Y., Baeyens, W. R., Huang, C., Fei, G., He, L., \& Ouyang, J. (2009). Enhanced separation of seven quinolones by capillary electrophoresis with silica nanoparticles as additive. Talanta, 77(5), 1667-1674. 